\title{
INCORPORACIÓN COMO MIEMBRO HONORARIO DEL MAESTRO FERNANDO VIDAL RAMÍREZ AL INSTITUTO DE LA FAMILIA
}

\author{
INCORPORATION AS HONORARY MEMBER OF MAESTRO \\ FERNANDO VIDAL RAMÍREZ TO THE FAMILY INSTITUTE
}

Fernando Arias-Stella Castillo ${ }^{1}$

Señor Doctor Mario Romero Antola, Decano de la Facultad de Derecho de la Universidad Femenina del Sagrado Corazón, Señora Licenciada Liliana Seminario Méndez, Directora del Programa de Derecho, Señora Doctora Teresa Cornejo Fava, Directora de la Revista "Persona y Familia" del Instituto de la Familia, Señores Autoridades, Señores Profesores, Señoritas Alumnas, Señoras y Señores:

Permítanme comenzar estas palabras de incorporación señalando el profundo honor que supone poder presentar al maestro Fernando Vidal Ramírez como miembro honorario de nuestro Instituto de la Familia. Permítanme igualmente, compartir con ustedes la feliz coincidencia que supone presentar en esta casa de estudios, tan identificada con los valores humanistas cristianos, el hecho que el maestro Fernando Vidal Ramírez fue mi profesor del curso de Contratos, en la Pontificia Universidad Católica.

Un punto de inicio en la biografía del maestro Fernando Vidal Ramírez es obviamente su nacimiento. Los padres del maestro Fernando Vidal Ramírez fueron el periodista Luis Vidal Sologuren y la señora María Jesús Ramírez Mansilla. Nace un 23 de agosto de 1934 en la Calle Piedra, hoy $3^{\circ}$ Cuadra del Jirón Callao. Su Bisabuelo Napoleón Rufino Vidal combatió en la Batalla de Tacna y su memoria marcó en su familia una impronta de reivindicación patriótica respecto a la recuperación de Tacna y de amor al Perú en general.

En su vida familiar, formó un matrimonio ejemplar que perdura hasta hoy día con la señora María Victoria Castellanos, con quien tiene dos hijos: Liliana Vidal Castellanos de Nicholls, reconocida abogada tributarista y Fernando Vidal Castellanos, Vicario General del Sodatithium Christianae Vitae.

\footnotetext{
Abogado, docente de la Facultad de Derecho. Tuvo a su cargo el discurso de incorporación del Dr. Fernando Vidal Ramírez como Miembro Honorario del Instituto de la Familia en ceremonia realizada el 26 de noviembre de 2014 en el Salón de Conferencias de la UNIFÉ.
} 
Su formación espiritual adhirió rápidamente los valores humanistas cristianos que hoy ostenta, desde que comenzó sus estudios escolares en los Colegios Religiosos de Santa Ana de San Miguel y Claretiano. Tempranamente conoció el éxito académico, pues obtuvo la beca internacional para un seminario en la Universidad de Indiana, donde conocerá al famoso jurista Jerome Hall y su visión desarrollista de la Ciencia Jurídica. En dicha oportunidad, tuvo la grata experiencia de compartir sus estudios con el recordado maestro Valentín Paniagua Corazao, como el mismo relata en el artículo que preparó especialmente para el libro homenaje editado en memoria del Doctor Valentín Paniagua Corazao.

Casi simultáneamente, se convirtió en Catedrático de la Facultad de Derecho de San Marcos, siendo heredero de los Cursos de Derecho Civil del Maestro José María León Barandiarán. Igualmente, es rápidamente invitado por la Pontificia Universidad Católica para enseñar entre otros, los emblemáticos cursos de Acto Jurídico y Contratos. Y, años más tarde, la Universidad de Lima también lo convocó para enseñar en la entonces flamante Facultad de Derecho. Y, nuestra propia facultad, con la recordada ex decana, Gabriela Aranibar Fernández Dávila, lo invitó a su planta docente en 1991 donde alcanzó el grado de Profesor Extraordinario en calidad de Emérito el 2 de noviembre del 2007.

Esta vocación académica lo llevó a ser designado Miembro Destacado de la Comisión Reformadora del Código Civil de 1936 y con ello, uno de los ponentes más respetados en el área del Acto Jurídico. Siendo sus propios maestros y amigos, José León Barandiarán, Carlos Fernández Sessarego y Felipe Osterling Parodi, quienes lo han reconocido públicamente en sus propias memorias como uno de los responsables de la flamante Escuela de Derecho Civil en el Perú. Siendo autor del clásico "El Acto Jurídico", obra que recibió el premio José León Barandiarán del Consejo Nacional de Ciencia y Tecnología de 1989, que ya lleva más de ocho ediciones, además de otras obras como "El Manual del Derecho Arbitral", "La Cesión de Derechos en el Código Civil", "Prescripción Extintiva y Caducidad", "Introducción al Derecho Civil Peruano" y "La Bolsa de Valores". También ha sido entusiasta colaborador de revistas académicas como la Revista del Foro ("El Debido Proceso y la Corte Interamericana de Derechos Humanos"), la Revista Lumen ("La Corresponsabilidad de Varones y Mujeres") entre otras.

Abogado de nota, funda el Estudio Rodríguez Mariátegui \& Vidal, donde rápidamente también, se ganó fama como experto en temas comerciales y de arbitraje y especialmente, en temas bursátil, por lo que resultó merecido 
Presidente de la Bolsa de Valores de Lima desde 1972 hasta 1984 y luego, Presidente de la Federación Iberoamericana de Bolsas.

Inició su carrera gremialista siendo vocero del recordado maestro Max Arias Schreiber y luego, el mismo es elegido Decano del Ilustre Colegio de Abogados de Lima en el año de 1988, restableciendo la institucional Academia Peruana de Derecho.

A lo largo de su vida profesional ha recibido numerosas condecoraciones, siendo de mencionar especialmente, la Máxima Condecoración del Colegio de Abogados del Callao: Orden José Gálvez Egusquiza y la Máxima Condecoración del Colegio de Abogados de Lima: Orden Vicente Morales Duarez. Así como el Premio de la Unión Iberoamericana de Colegio de Abogados.

Es importante destacar que la brillantez del maestro Fernando Vidal no se agota en el Derecho Civil o en la práctica privada, sino que tiene el logro de haber sido miembro destacado de la emblemática Comisión Consultiva del Ministerio de Relaciones Exteriores, lo que luego lo catapultó a ser designado Miembro de la muy reconocida Comisión Bilateral encargada de presentar propuestas para la ejecución de las cláusulas pendientes del Tratado de 1929, en donde compartió responsabilidades con sus pares chilenos, los muy ilustres Embajadores Edmundo Vargas y Luis Winter Igualt. Asimismo, le correspondió ser designado juez Ad-hoc en la Corte Interamericana de Derechos Humanos.

Fiel a su designio, Fernando Vidal Ramírez no ha dudado en hacer frente a las encrucijadas de la vida con hombría de bien y respeto a la verdad. Así lo demostró como estudiante en San Marcos, como becario en Bloomington haciendo causa común con Valentín Paniagua, como catedrático en la Universidad Católica cuando hubo que hacer frente a los intolerantes y revoltosos, como abogado al frente del Colegio de Abogados, como patriota en los foros internacionales y en general como demócrata frente a la defensa del estado constitucional de Derecho.

Finalmente, como corresponde a su natural vocación de servicio cívico y democrático, ha sido elegido Presidente del Tribunal de Honor del Pacto Ético Electoral. Por todo ello, reitero el profundo orgullo que representa para nosotros incorporar al maestro Fernando Vidal Ramírez como miembro de honor del Instituto de la Familia. 
